\title{
Safety and pharmacokinetics of paclitaxel and the oral mTOR inhibitor everolimus in advanced solid tumours
}

\author{
M Campone', V Levy², E Bourbouloux', D Berton Rigaud', D Bootle ${ }^{3}$, C Dutreix $^{3}$, U Zoellner $^{3}, \mathbf{N ~ S h a n d ~}^{3}$, \\ F Calvo ${ }^{2}$ and E Raymond*,2,4
}

'Department of Medical Oncology, Centre René Gauducheau, Nantes, Cedex 44805, France; ${ }^{2}$ Department of Medical Oncology, Hôpital Saint Louis AP-HP, Paris, Cedex 10, France; ${ }^{3}$ Novartis Pharma AG, Basel, 4002 Switzerland; ${ }^{4}$ Hôpital Beaujon, Clichy, France

Everolimus displays antiproliferative effects on cancer cells, yields antiangiogenic activity in established tumours, and shows synergistic activity with paclitaxel in preclinical models. This study assessed the safety and the pharmacokinetic interactions of everolimus and paclitaxel in patients with advanced malignancies. Everolimus was dose escalated from 15 to $30 \mathrm{mg}$ and administered with paclitaxel $80 \mathrm{mg} \mathrm{m}^{-2}$ on days I, 8, and 15 every 28 days. Safety was assessed weekly, and dose-limiting toxicity (DLT) was evaluated in cycle I. A total of 16 patients (median age 54.5 years, range 33-69) were entered; II had prior taxane therapy for breast ( $n=5)$, ovarian $(n=3)$, and vaginal cancer $(n=1)$ or angiosarcoma $(n=2)$. Grade 3 neutropenia in six patients met the criteria for DLT in two patients receiving everolimus $30 \mathrm{mg}$ weekly. Other drug-related grade 3 toxicities were leucopenia, anaemia, thrombocytopenia, stomatitis, asthenia, and increased liver enzymes. Tumour stabilisation reported in II patients exceeded 6 months in 2 patients with breast cancer. Everolimus showed an acceptable safety profile at the dose of $30 \mathrm{mg}$ when combined with weekly paclitaxel $80 \mathrm{mg} \mathrm{m}^{-2}$, warranting further clinical investigation.

British Journal of Cancer (2009) I 00, 315-321. doi:10.1038/sj.bjc.660485 I www.bjcancer.com

Published online 6 January 2009

(c) 2009 Cancer Research UK

Keywords: RAD00 I; everolimus; paclitaxel; phase I; drug interaction; combination chemotherapy

The mammalian target of rapamycin (mTOR) is an important kinase downstream in the PI3-kinase/Akt signalling pathway. It modulates signals from growth factors and intracellular sensors of nutrients and hypoxia to control translation of proteins involved in cellular growth, proliferation, and responses to nutrient deprivation and hypoxic stress, resulting in the stimulation of angiogenesis, facilitation of $\mathrm{G}_{1}-\mathrm{S}$ transition of the cell cycle, and inhibition of radiation or cytotoxic drug-induced apoptosis in a variety of human tumours (Faivre et al, 2006). Cancer cells commonly have mutations and/or overexpression of several signalling molecules, resulting in the activation of mTOR and its substrates $\mathrm{S} 6 \mathrm{~K} 1$ and 4E-BP1. For example, the HER2 overexpression observed in about one-third of breast cancers is associated with activation of PI3-kinase/Akt/mTOR signalling (Bacus et al, 2002; Zhou et al, 2004), resistance to stress-induced apoptosis (Bacus et al, 2002), and tumour aggressiveness (Cobleigh et al, 1999; Zhou et al, 2004). Activation of the PI3-kinase/Akt/ mTOR signalling pathway may be inhibited by rapamycin, which blocks mTOR activation, resulting in the inhibition of tumour growth (see reviews by Faivre et al, 2006; Georgakis and Younes, 2006).

Everolimus (RAD001) is an oral mTOR inhibitor derived from rapamycin, which blocks the activation of $\mathrm{S} 6 \mathrm{~K} 1$ and $4 \mathrm{E}-\mathrm{BP} 1$, thereby inhibiting cell growth, proliferation, and $\mathrm{G}_{1}-\mathrm{S}$ transition, and inducing apoptosis (Boulay et al, 2004). Everolimus displays

\footnotetext{
* Correspondence: Dr E Raymond;

E-mail: eric.raymond@bjn.aphp.fr

Revised 12 November 2008; accepted 2 December 2008; published online 6 January 2009
}

direct effects on growth and proliferation of cancer cells and inhibits angiogenesis by preventing the proliferation of endothelial cells in human tumour xenografts (Beuvink et al, 2001; Lane et al, 2003). In single-agent phase I studies of everolimus performed in patients with advanced cancers, a safe toxicity profile along with evidence of sustained tumour stabilisation at weekly doses of $10-$ $70 \mathrm{mg}$ was shown (O'Donnell et al, 2008; Tabernero et al, 2008). Dose-limiting toxicities (DLTs) observed at $70 \mathrm{mg}$ included grade 3 stomatitis, neutropenia, and hyperglycaemia (Tabernero et al, 2008). Consistent inhibition of S6K1 activity in peripheral blood mononuclear cells was seen with doses $\geqslant 20 \mathrm{mg}$ per week and was sustained for at least 7 days at doses $\geqslant 20 \mathrm{mg}$ per week (O'Donnell et al, 2008). Furthermore, immunohistochemical analysis in paired tumour tissue biopsies taken before and during weekly dosing $(20$, 50 , or $70 \mathrm{mg}$ ) confirmed inhibition of S6K1 at doses $\geqslant 20 \mathrm{mg}$ (Tabernero et al, 2008).

Paclitaxel remains a standard treatment for a variety of cancers, including lung, breast, head and neck, and ovary, and may be administered weekly to reduce haematological toxicity either alone or in combination with other anti-tumour agents on an every-week (Green et al, 2005; Le et al, 2006; Schuette et al, 2006; Yamamoto et $a l, 2006$ ) or a weekly for 3 weeks monthly schedule (Perez et al, 2005; Yeh et al, 2005; Ramalingam et al, 2006; Stathopoulos et al, 2007). Several tumour types that display sensitivity to paclitaxel also show activation of the PI3-kinase/Akt/mTOR signalling pathway (Shayesteh et al, 1999; Hu et al, 2000; Perez-Tenorio et al, 2002; David et al, 2004; Samuels et al, 2004; Saal et al, 2005). Paclitaxel resistance appears multifactorial, involving overexpression of P-glycoprotein, mutation of $\beta$-tubulin, and defects of apoptosis (Yusuf et al, 2003). There is also consistent evidence that 
the PI3-kinase/Akt/mTOR signalling pathways may be associated with resistance to taxanes and other drugs acting on microtubules. In cancer cells, inhibition of the PI3-kinase/Akt/mTOR signalling pathway (Hu et al, 2002; Yu et al, 2005), including inhibition of mTOR with rapamycin, was shown to counteract Akt-mediated resistance to drugs inhibiting tubulin (Vanderweele and Rudin, 2005) and to restore apoptosis (Faried et al, 2006).

In vivo combinations of everolimus with paclitaxel showed additive and synergistic effects in tumour models but with a schedule effect, in that administration of everolimus 1 day before or after paclitaxel reduced anti-tumour activity (O'Reilly et al, 2003). These preclinical data served as a rationale to further investigate the safety and potential pharmacokinetic interactions of everolimus in combination with paclitaxel in patients with tumours potentially sensitive to paclitaxel-based chemotherapy. To avoid effects related to scheduling and accumulation, everolimus and paclitaxel were administered together on the first day of each week, and in week 4 of each cycle treatment, it was omitted to allow recovery of cells from mTOR inhibition.

\section{MATERIALS AND METHODS}

This open-label dose-escalation study was approved by the French National Ethics Committee and was conducted in accordance with the Declaration of Helsinki Principles and Good Clinical Practice. A signed informed consent was required of each patient.

\section{Eligibility criteria}

Eligible patients were at least 18 years of age with pathologically confirmed locally advanced or metastatic cancer refractory to or unsuitable for standard chemotherapy, but they were potentially able to benefit from paclitaxel chemotherapy. Life expectancy was $\geqslant 6$ months with a World Health Organization (WHO) performance status of $0-2$. Patients also had adequate bone marrow (absolute neutrophil count $\geqslant 1.5 \times 10^{9} \mathrm{l}^{-1}$, platelets $\geqslant 100 \times 10^{9} \mathrm{l}^{-1}$, haemoglobin $>10 \mathrm{~g}$ per $100 \mathrm{ml}$ ), liver function (serum transaminase $\leqslant 3$ times upper limit of normal (ULN), serum albumin and bilirubin within reference ranges), and kidney function (creatinine $\leqslant 1.5$ times ULN).

Patients were ineligible if they had primary or metastatic central nervous system cancer, a history of HIV seropositivity, or active bleeding diathesis; were taking oral anti-vitamin $\mathrm{K}$ medication (except low-dose coumadin); had uncontrolled infection, impaired gastrointestinal function, or disease that might alter absorption of everolimus; or had received an investigational drug within the previous 30 days. Women who were pregnant, breast-feeding, or able to conceive but unwilling to practice effective contraception, and patients with known Cremophor allergy were also excluded.

\section{Study drug administration and monitoring}

Everolimus (RAD001; Novartis Pharmaceuticals, Basel, Switzerland) and paclitaxel (Bristol-Myers Squibb Pharmaceuticals Ltd, New York, NY, USA) were administered on days 1,8 , and 15 on an every-28-day cycle for up to 6 cycles. Everolimus was given orally immediately before paclitaxel, which was administered by intravenous infusion over $60 \mathrm{~min}$. Patients receiving at least one dose of study drug medications were evaluated weekly for safety using the National Cancer Institute Common Toxicity Criteria version 2.0. Safety assessments consisted of clinical examinations and scheduled laboratory evaluations and electrocardiograms. The paclitaxel-everolimus combination was interrupted on the occurrence of any grade 3 non-haematological toxicity or grade $\geqslant 2$ thrombocytopenia or neutropenia until recovery to grade $\leqslant 1$. Treatment with the combination was discontinued on any grade 4 toxicity or failure to return to grade $\leqslant 1$ within 2 weeks.
Prophylaxis of emetic and allergic reactions to paclitaxel using ondansetron, granisetron, and steroids was allowed. The concomitant use of any drugs that may interfere with cytochrome CYP450-3A was discouraged. After paclitaxel discontinuation at the completion of six cycles, everolimus could be maintained weekly until tumour progression. Anti-tumour activity was assessed using Response Evaluation Criteria in Solid Tumors.

\section{Dose escalation and definition of DLT}

Because everolimus could potentially increase exposure to paclitaxel and, at higher doses than used in this study, had shown significant haematological toxicity, the safety of the combination was explored in patients in whom the standard weekly dose of paclitaxel $80 \mathrm{mg} \mathrm{m}^{-2}$ was combined initially with one-half the single-agent recommended dose of everolimus ( $15 \mathrm{mg}$ weekly, dose level 1) and then escalated to $30 \mathrm{mg}$ weekly (dose level 2). Doselimiting toxicity was defined as occurring during the first 28-day cycle, suspected of being drug related, and included any grade 4 toxicity, any grade 3 non-haematological toxicity despite preventive therapy, or grade $\geqslant 2$ neutropenia, or thrombocytopenia failing to revert to grade $\leqslant 1$ within 2 weeks. Three patients were entered per dose level, with expansion to six patients if one of three patients experienced DLT. If DLT occurred in none of three or no more than one of six patients in dose level 1, doses would be escalated to dose level 2. Dose-limiting toxicity in more than one of three or more than two of six patients would be considered unacceptable. After the highest well-tolerated dose of everolimus ( 15 or $30 \mathrm{mg}$ ) in combination with paclitaxel was established, the size of this cohort would be expanded to 12 patients to obtain additional safety information on cumulative toxicity. With a sample size of 12 patients, the expanded cohort had a probability of 72 and $99 \%$ of detecting any toxicity that occurs with an incidence of 10 and $30 \%$, respectively.

\section{Pharmacokinetic measurements}

In week 1 of cycle 1 , blood samples were taken together to measure pharmacokinetic parameters of both everolimus and paclitaxel. At cycle 2, everolimus was withheld on day 1, allowing the determination of blood levels of paclitaxel alone, without interference from everolimus, which shows a terminal half-life of about $30 \mathrm{~h}$ as a single agent. Pharmacokinetic parameters of everolimus were determined in week 2 of cycle 2, 1 week following the last administration of paclitaxel, which displays a terminal half-life of about $10 \mathrm{~h}$ as a single agent. For paclitaxel, sampling was carried out before and at the end of the infusion and at 15 and $30 \mathrm{~min}$, and $1,2,4,9,24,36,48$, and $96 \mathrm{~h}$ after completion of the infusion. For everolimus, sampling was carried out predose and 1, $2,4,6,12,24,48,96$, and $168 \mathrm{~h}$ after administration. Everolimus was measured in whole blood by liquid chromatography-mass spectrometry after liquid extraction, its lower limit of quantification being $0.368 \mathrm{ng} \mathrm{ml}^{-1}$. Paclitaxel was measured in plasma by high-pressure liquid chromatography with ultraviolet detector, lower limit of quantification being $10 \mathrm{ng} \mathrm{ml}^{-1}$. Pharmacokinetic parameters were derived by standard non-compartmental methods of analysis (WinNonlin Pro 5.0). The measured parameters included the maximum plasma concentration $\left(C_{\max }\right)$, time to reach $C_{\max }\left(t_{\max }\right)$, and the truncated area under the timeconcentration curve $\left(\mathrm{AUC}_{\text {last }}\right)$.

\section{RESULTS}

\section{General}

A total of 16 patients with advanced solid tumours were enrolled in this study (Table 1). Most were considered heavily pre-treated, with a median of three prior chemotherapy regimens (range $0-10$ 
Table I Patient characteristics

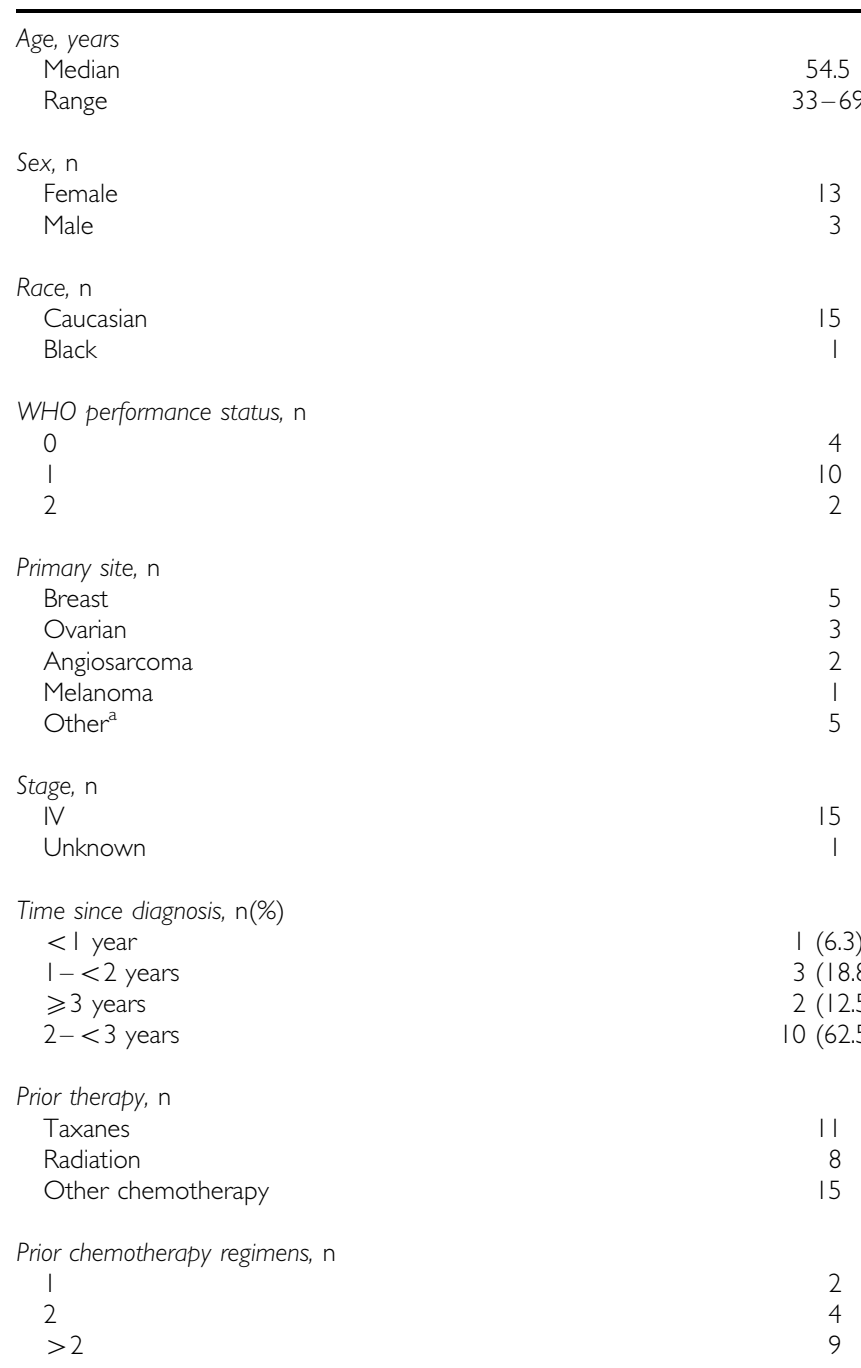

$\mathrm{WHO}=$ World Health Organization. ${ }^{\mathrm{a}}$ One each in dose level 2: thyroid carcinoma, mixed testicular (mature embryonic and immature teratoma) cancer, abdominal liposarcoma, vaginal cancer, cholangiocarcinoma.

regimens). None of the three patients entered at dose level 1 experienced DLT in cycle 1, allowing escalation to dose level 2. At dose level 2, none of the first 6 patients experienced DLT in cycle 1; thus, this cohort was expanded (Table 2) to 13 patients (one patient who experienced tumour progression on day 8 of cycle 1 was not fully evaluable for safety). Among 12 patients evaluable for toxicity at dose level 2, 2 patients experienced DLTs; one with grade 3 neutropenia, the other with grade 3 neutropenia and grade 2 thrombocytopenia. The toxicities recovered within 2 weeks but were interpreted as de facto DLTs, because the paclitaxel dose was immediately reduced by $25 \%$ for subsequent cycles in conformity with the manufacturer's recommendations. Median duration of everolimus and paclitaxel at dose level 2 was three cycles; three patients completed six cycles, including two patients with metastatic breast cancer who continued to receive single-agent everolimus for 8 and 18 weeks after paclitaxel discontinuation.

Safety No toxicity-related death was reported. The most frequently reported adverse events of any grade irrespective of causality occurring in any treatment cycle were asthenia $(81.3 \%)$, neutropenia (62.5\%), alopecia and anaemia (each $43.8 \%$ ), and
Table 2 Treatment administration by dose level

\begin{tabular}{|c|c|c|c|}
\hline & $\begin{array}{c}\text { Dose level I } \\
\text { everolimus } \\
15 \mathrm{mg}\end{array}$ & $\begin{array}{c}\text { Dose level } 2 \\
\text { everolimus } \\
30 \mathrm{mg}\end{array}$ & All \\
\hline Treated, $n$ & 3 & 13 & 16 \\
\hline \multicolumn{4}{|l|}{ Discontinued, $\mathrm{n}$} \\
\hline Due to AEs & 0 & I & 1 \\
\hline $\begin{array}{l}\text { Due to PD, tumour } \\
\text { complications }\end{array}$ & 3 & 11 & 14 \\
\hline For other reason & 0 & । & । \\
\hline \multicolumn{4}{|l|}{ Cycles completed, ${ }^{a} \mathrm{n}$} \\
\hline 0 & 0 & । & । \\
\hline 1 & 0 & I & I \\
\hline 2 & I & 3 & 4 \\
\hline 3 & 0 & 4 & 4 \\
\hline 4 & 2 & 1 & 3 \\
\hline 5 & 0 & 0 & 0 \\
\hline $6^{\mathrm{b}}$ & 0 & 3 & 3 \\
\hline $\begin{array}{l}\text { Mean everolimus treatment } \\
\text { duration, weeks }\end{array}$ & 12.6 & 13.8 & 13.6 \\
\hline $\begin{array}{l}\text { Median everolimus } \\
\text { treatment duration, weeks }\end{array}$ & 14.1 & 11.9 & 12.5 \\
\hline Range, weeks & $9-15$ & $|-4|$ & $|-4|$ \\
\hline $\begin{array}{l}\text { Dose interruptions in any } \\
\text { cycle, } n(\%)\end{array}$ & I (33.3) & $7(53.8)$ & $8(50.0)$ \\
\hline
\end{tabular}

$\mathrm{AE}=$ adverse event; $\mathrm{PD}=$ progressive disease. ${ }^{\mathrm{a} C y c l e s}$ completed refers to the number of combined everolimus with paclitaxel 4-week cycles. ${ }^{\mathrm{b}}$ Among the three patients completing six cycles of everolimus $30 \mathrm{mg}$ with paclitaxel therapy, the customary maximum for paclitaxel, two patients with metastatic breast cancer continued to receive everolimus for 8 and 18 weeks.

stomatitis, nausea, and pyrexia (each $37.5 \%$ ). Grade $3 / 4$ adverse events reported in 11 patients included 1 patient with an unrelated grade 4 necrosis of the toe. The most frequently reported drugrelated toxicities (Table 3 ) included neutropenia (56.3\%), alopecia and asthenia (each 43.8\%), and anaemia and stomatitis (each $37.5 \%)$. Thirteen drug-related grade 3 toxicities reported in eight patients, all at dose level 2 , included neutropenia in six patients $(37.5 \%)$, leucopenia in two patients $(12.5 \%)$, and anaemia, thrombocytopenia, asthenia, stomatitis, and increased alanine aminotransferase levels in individual patients. No drug-related grade 4 toxicity was reported. Serious adverse events occurred in six patients, four directly linked with tumour progression; the other two included a case of grade 3 erysipelas and grade 1 neutropenia in a patient with skin melanoma, and grade 3 interstitial pneumonitis at cycle 6 in another with metastatic breast cancer. In the latter patient, interstitial pneumonitis was confirmed by bronchoscopy and was reversible under treatment with corticosteroids.

Pharmacokinetics Blood samples were obtained from 11 patients, including 3 patients treated at dose level 1 and 8 patients at dose level 2. Three patients at dose level 2 did not provide blood samples for determination of everolimus pharmacokinetics. In addition, one patient treated at dose level 2 displayed a threefold increase of everolimus AUC that was found to be related to concomitant medication with fluconazole, invalidating any possible assessment of drug interaction between paclitaxel and everolimus.

Representative pharmacokinetic curves of patients treated at dose level 2 are shown in Figure 1, and the main pharmacokinetic parameters of everolimus and paclitaxel are shown in Table 4. As shown, no meaningful change in $t_{\max }, C_{\max }$, and $\mathrm{AUC}_{\text {last }}$ of paclitaxel and everolimus was detectable when the drugs were given in combination. 
Table 3 Drug-related toxicity of everolimus in combination with paclitaxel (reported in > I patient or of grade 3)

\begin{tabular}{|c|c|c|c|c|c|c|}
\hline & \multicolumn{2}{|c|}{ Dose level I everolimus I 5 mg } & \multicolumn{2}{|c|}{ Dose level 2 everolimus $30 \mathrm{mg}$} & \multirow{2}{*}{\multicolumn{2}{|c|}{$\begin{array}{c}\text { All } \\
\mathbf{N}=16\end{array}$}} \\
\hline & \multicolumn{2}{|c|}{$\mathbf{n}=\mathbf{3}$} & \multicolumn{2}{|c|}{$n=13$} & & \\
\hline & All & Grade 3 & All & Grade 3 & All & Grade 3 \\
\hline Any & 3 & - & || & 8 & 14 & 8 \\
\hline Neutropenia & 2 & - & 7 & 6 & 9 & 6 \\
\hline Alopecia & I & - & 6 & - & 7 & - \\
\hline Asthenia & । & - & 6 & । & 7 & 1 \\
\hline Anaemia & 2 & - & 4 & I & 6 & I \\
\hline Stomatitis & । & - & 5 & । & 6 & I \\
\hline Leucopenia & । & - & 4 & 2 & 5 & 2 \\
\hline Myalgia & I & - & 4 & - & 5 & - \\
\hline Paresthesia & I & - & 3 & - & 4 & - \\
\hline Thrombocytopenia & 0 & - & 4 & I & 4 & I \\
\hline Arthralgia & 0 & - & 3 & - & 3 & - \\
\hline Erythema & 0 & - & 3 & - & 3 & - \\
\hline Nausea & 2 & - & I & - & 3 & - \\
\hline Skin lesions & 0 & - & 3 & - & 3 & - \\
\hline Abdominal pain (upper) & । & - & 1 & - & 2 & - \\
\hline Diarrhoea & । & - & । & - & 2 & - \\
\hline Headache & । & - & 1 & - & 2 & - \\
\hline Pruritus & 0 & - & 2 & - & 2 & - \\
\hline Pyrexia & । & - & I & - & 2 & - \\
\hline Vomiting & । & - & 1 & - & 2 & - \\
\hline ALT increase & 0 & - & i & 1 & I & I \\
\hline
\end{tabular}

$\mathrm{ALT}=$ alanine aminotransferase.

Response to therapy No objective response was observed. Sustained tumour stabilisation for more than 4 months was observed in six patients, including those with breast cancer (two patients), ovarian carcinoma (two patients), thyroid carcinoma (one patient), and liposarcoma (one patient). In two patients with metastatic breast cancer treated at dose level 2, tumour stabilisation that lasted $>6$ months exceeded the duration of tumour stabilisation previously recorded with docetaxel therapy (3.7 and 3.5 months).

\section{DISCUSSION}

Genetic defects in cancer cells expressed as the constitutive activation of growth factor signalling pathways provide stimulation for continued cell growth, survival, and resistance to chemotherapy. In tumours addicted to this growth factor stimulation, chemotherapy combined with mTOR inhibition has shown synergistic anti-tumour effects. For example, data have shown that rapamycin and everolimus can enhance the antitumour activity of paclitaxel (O'Reilly et al, 2003; Mondesire et al, 2004; Faried et al, 2006; Aissat et al, 2007; Haritunians et al, 2007) in a manner related in occurrence and extent to the tumour, dose, and interestingly, the sequence of administration of the mTOR inhibitor and paclitaxel (O'Reilly et al, 2003; Mondesire et al, 2004; Faried et al, 2006; Aissat et al, 2007). In vitro, paclitaxel treatment before mTOR inhibition produced greater enhancement of apoptosis than treatment after or simultaneously with the mTOR inhibitor, which may reflect a conflict between the slowing of the cell cycle through the $G_{1}-S$ transition by mTOR inhibition and the requirement that cells be in $\mathrm{G}_{2}-\mathrm{M}$ transition for paclitaxelinduced apoptosis (Mondesire et al, 2004; Aissat et al, 2007). Alternatively or in addition, enhancement of cytotoxicity may directly involve p70S6 kinase, which is activated by mTOR. Direct inactivation of p70S6 kinase in mitotic breast and ovarian cancer by paclitaxel has been proposed as a mechanism through which paclitaxel may exert an anti-tumour effect (Le et al, 2003). p70S6 kinase inactivates the pro-apoptotic factor BAD; mTOR inhibitors or paclitaxel may promote apoptosis by preventing this inactivation. Consistent with these mechanisms, it has been shown that breast cancer cells resistant to the growth inhibiting effects of rapamycin are also resistant to its chemosensitising effects (Mondesire et al, 2004), and sequence-dependent enhancement of paclitaxel cytotoxicity has also been seen with gefitinib and trastuzumab, agents that like mTOR inhibitors inhibit growth factor signal transduction (Lee et al, 2002; Magné et al, 2002). However, in another study with cervical cancer cells, treatment with rapamycin preceding paclitaxel produced the more favourable result (Faried et al, 2006), suggesting that sequence dependency may be influenced by different mechanisms in other types of cancer. Inhibition of protein synthesis by mTOR inhibition may additionally contribute to apoptosis by preventing repair of paclitaxel-induced cell damage (Aissat et al, 2007). The extent to which sequence dependency translates in vivo is also not clear. In one study, simultaneous treatment with everolimus and paclitaxel produced the greatest enhancement of paclitaxel activity (O'Reilly et al, 2003), whereas in another study with xenografts derived from breast cancer cells in which sequence effects were seen in vitro, no sequence effects were observed in vivo (Mondesire et al, 2004). In this trial based on our earlier work (O'Reilly et al, 2003), everolimus was administered weekly immediately before paclitaxel infusion to avoid or minimise scheduling effects.

In a report on the pharmacodynamics of weekly paclitaxel in cervical cancer patients, paclitaxel could be detected in tissue for up to 6 days and could induce apoptosis for up to 1 week after treatment, but after 2 weeks, it could no longer be detected in the tumour (Mori et al, 2007). The selection of $30 \mathrm{mg}$ per week as the dosage for everolimus was based on the results of a phase I study in which single doses of everolimus of up to $30 \mathrm{mg}$ had been shown to be satisfactorily safe and capable of inhibiting a biomarker indicative of target activity (S6K1 activity in peripheral blood mononuclear cells) (O'Donnell et al, 2008). Furthermore, based on the assumption that to be efficacious, the drug should achieve target inhibition that is at least as great as that associated with efficacy in the rat model (Tanaka et al, 2008), and accepting the modelling assumption of a similar pharmacokinetic-pharmaco- 
dynamic relationship for tumour in patients and in rats, $20-30 \mathrm{mg}$ was identified as the minimal weekly dose. In addition, immunohistochemical analyses in paired tumour biopsies taken

A
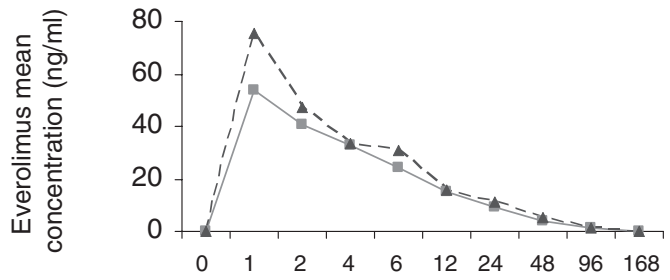

B

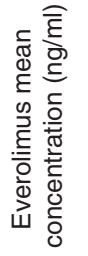

Everolimus $30 \mathrm{mg}$ weekly

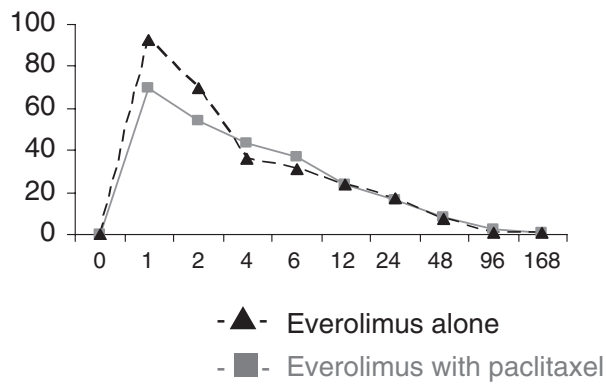

C

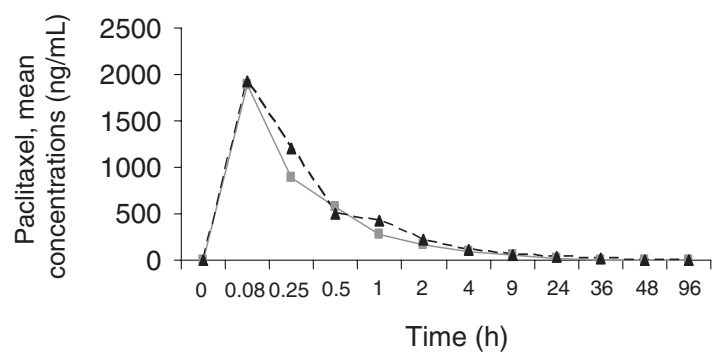

- A - Paclitaxel with everolimus

Paclitaxel alone

Figure I Pharmacokinetic profiles of everolimus in combination with paclitaxel. (A) Mean plasma concentration of everolimus following oral administration of $15 \mathrm{mg}$ everolimus alone $(n=3)$ or combined with a I-h infusion of paclitaxel $\left(80 \mathrm{mg} \mathrm{m}^{-2}\right)$. (B) Mean plasma concentration of everolimus following oral administration of $30 \mathrm{mg}$ everolimus alone $(n=4)$ or combined with a I-h infusion of paclitaxel $\left(80 \mathrm{mg} \mathrm{m}^{-2}\right)$. (C) Mean plasma concentration of paclitaxel following a I-h infusion of $80 \mathrm{mg} \mathrm{m}^{-2}$ paclitaxel alone $(n=7)$ or combined with 15 and $30 \mathrm{mg}$ everolimus. before and during weekly dosing $(20,50$, or $70 \mathrm{mg})$ confirmed inhibition of S6K1 at doses $\geqslant 20 \mathrm{mg}$ (Tabernero et al, 2008). Consequently, in this study, a weekly dose of everolimus, 15 or $30 \mathrm{mg}$ for 3 weeks followed by a 1-week rest period, was selected as likely to allow adequate inhibition of mTOR signalling, with a period of recovery between doses in the event that relief of mTOR inhibition or paclitaxel exposure enhances the apoptosis-inducing effects of this combination. A lower paclitaxel dose intensity with the 3-weeks-on, 1-week-off schedule compared with a continuous weekly schedule may compromise anti-tumour activity, although paclitaxel regimens with doses of $70-100 \mathrm{mg} \mathrm{m}^{-2}$ administered for 3 weeks of each 4 -week cycle have been used in combination with cytotoxic agents in patients with advanced cancers with encouraging evidence of anti-tumour activity and acceptable tolerability (Perez et al, 2005; Yeh et al, 2005; Ramalingam et al, 2006; Stathopoulos et al, 2007). With this regimen, we have shown that the toxicity of paclitaxel was not enhanced in combination with everolimus.

The most commonly reported drug-related adverse events were haematological toxicity, alopecia, asthenia, and stomatitis. Interstitial pneumonitis has been recognised as being associated with sustained treatment with rapamycin and other rapamycin derivatives (Pham et al, 2004; El-Maraghi et al, 2006). Pulmonary toxicity is a potential toxicity associated with the use of newer anti-neoplastic agents (Vahid and Marik, 2008). In this study, interstitial pneumonitis was of short duration and recovered under corticosteroid therapy. Interestingly, there was no apparent pharmacokinetic drug interaction between everolimus and paclitaxel. Although both drugs are metabolised by CYP450-3A, paclitaxel may be preferentially metabolised by CYP2C8. Further, steroids used in paclitaxel therapy such as dexamethasone, a weak inducer of CYP3A4, did not appear to affect everolimus.

Everolimus and paclitaxel may be co-administered with manageable toxicity. Everolimus $30 \mathrm{mg}$ can be safely administered with paclitaxel $80 \mathrm{mg}$ on a weekly schedule with dosing for 3 weeks on 4-week cycles for several months in human malignancies. No pharmacokinetic interactions were apparent, and neutropenia was the only toxicity considered dose limiting. It is noteworthy that previous attempts to combine mTOR inhibitors with cytotoxic agents were associated with an increased incidence of toxicity that included dose-limiting diarrhoea and stomatitis with 5-fluorouracil (Punt et al, 2003) and thrombocytopenia with gemcitabine (Pacey et al, 2004). In this regard, the feasibility of combining everolimus with paclitaxel at clinically effective doses of each agent and the delayed tumour progression observed in this heavily pretreated population warrant further investigation in paclitaxelsensitive tumours. Preliminary results of a phase I study combining everolimus and paclitaxel with trastuzumab in patients with trastuzumab-resistant breast cancer have been encouraging, in that the combination was adequately tolerated with a high rate of response $(46 \%)$ in a population pre-treated with both trastuzumab and taxanes (André et al, 2008).

Pharmacokinetic parameters of everolimus and paclitaxel

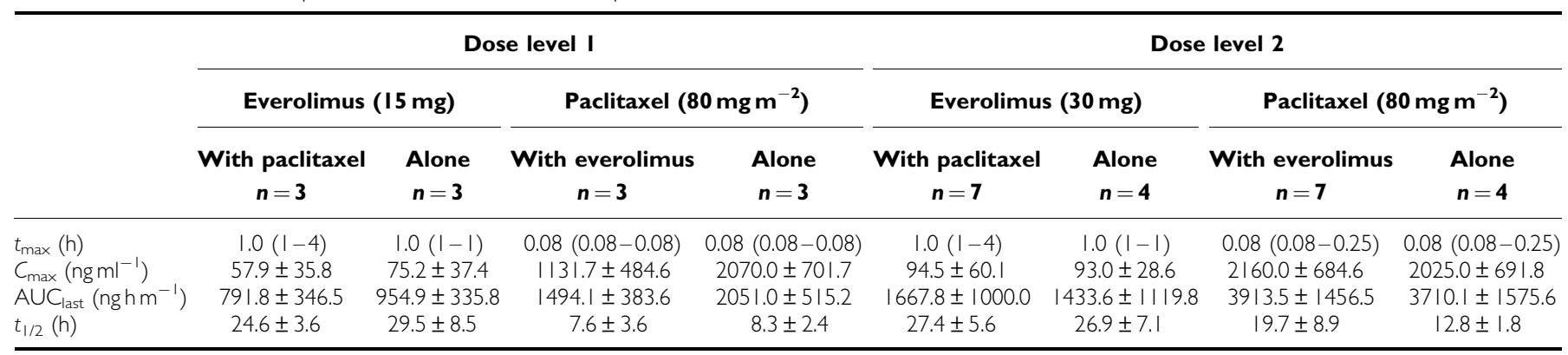

$t_{\max }$ values are median (range), the other parameters values are mean (s.d.). 


\section{ACKNOWLEDGEMENTS}

This research was supported by Novartis Pharma AG. This study was presented in part at the 16th EORTC-NCI-AACR Symposium on 'Molecular Targets and Cancer Therapeutics', Geneva, Switzerland. We acknowledge Dr Marie-Noelle Bizot of Novartis Pharma AG, who carried out the drug-level analyses for Everolimus, and the editorial assistance of Dr Richard McCabe.

\section{REFERENCES}

Aissat N, Le Tourneau C, Ghoul A, Serova M, Bieche I, Lokiec F, Raymond E, Faivre S (2007) Antiproliferative effects of rapamycin as a single agent and in combination with carboplatin and paclitaxel in head and neck cancer cell lines. Cancer Chemother Pharmacol 62: $305-313$

André F, Campone M, Hurvitz SA, Vittori L, Pylvaenaeinen I, Sahmoud T, O'Regaan RM (2008) Muticenter phase I clinical trial of daily and week RAD001 (everolimus) in combination with weekly paclitaxel and trastuzumab in patients with HER-2-overexpressing metastatic breast cancer with prior resistance to trastuzumab. J Clin Oncol 26(Suppl): 41s (Abstract 1003)

Bacus SS, Altomare DA, Lyass L, Chin DM, Farrell MP, Gurova K, Gudkov A, Testa JR (2002) AKT2 is frequently upregulated in HER-2/neu-positive breast cancers and may contribute to tumor aggressiveness by enhancing cell survival. Oncogene 21: $3532-3540$

Beuvink I, O'Reilly T, Zumstein S (2001) Antitumor activity of RAD001, an orally active rapamycin derivative. Proc Am Assoc Cancer Res 42: 366 (Abstract 1972)

Boulay A, Zumstein-Mecker S, Stephan C, Beuvink I, Zilbermann F, Haller R, Tobler S, Heusser C, O'Reilly T, Stolz B, Marti A, Thomas G, Lane HA (2004) Antitumor efficacy of intermittent treatment schedules with the rapamycin derivative RAD001 correlates with prolonged inactivation of ribosomal protein S6 kinase 1 in peripheral blood mononuclear cells. Cancer Res 64: 252-261

Cobleigh MA, Vogel CL, Tripathy D, Robert NJ, Scholl S, Fehrenbacher L, Wolter JM, Paton V, Shak S, Lieberman G, Slamon DJ (1999) Multinational study of the efficacy and safety of humanized anti-HER2 monoclonal antibody in women who have HER2-overexpressing metastatic breast cancer that has progressed after chemotherapy for metastatic disease. J Clin Oncol 17: 2639-2648

David O, Jett J, LeBeau H, Dy G, Hughes J, Friedman M, Brody AR (2004) Phospho-Akt overexpression in non-small cell lung cancer confers significant stage-independent survival disadvantage. Clin Cancer Res 10: $6865-6871$

El-Maraghi RH, Ellard S, Gelmon K, Mckintosh L, Seymour L (2006) Pulmonary adverse events in a randomised phase II study of the mTOR inhibitor RAD001C (everolimus): NCIC CTG IND.163. Eur J Cancer Suppl 4: 164 (Abstract 541)

Faivre S, Kroemer G, Raymond E (2006) Current development of mTOR inhibitors as anticancer agents. Nat Rev Drug Disc 5: 671-688

Faried LS, Faried A, Kanuma T, Nakazato T, Tamura T, Kuwano H, Minegishi $\mathrm{T}$ (2006) Inhibition of the mammalian target of rapamycin (mTOR) by rapamycin increases chemosensitivity of CaSki cells to paclitaxel. Eur J Cancer 42: 934-947

Georgakis GV, Younes A (2006) From Rapa Nui to rapamycin: targeting PI3K/Akt/mTOR for cancer therapy. Expert Rev Anticancer Ther 6: $131-140$

Green MC, Buzdar AU, Smith T, Ibrahim NK, Valero V, Rosales MF, Cristofanilli M, Booser DJ, Pusztai L, Rivera E, Theriault RL, Carter C, Frye D, Hunt KK, Symmans WF, Strom EA, Sahin AA, Sikov W, Hortobagyi GN (2005) Weekly paclitaxel improves pathologic complete remission in operable breast cancer when compared with paclitaxel once every 3 week. J Clin Oncol 23: 5983-5992

Haritunians T, Mori A, O'Kelly J, Luong QT, Giles FJ, Koeffler HP (2007) Antiproliferative activity of RAD001 (everolimus) as a single agent and combined with other agents in mantle cell lymphoma. Leukemia 21: $333-339$

Hu L, Hofmann J, Lu Y, Lu Y, Mills GB, Jaffe RB (2002) Inhibition of phosphatidylinositol $3^{\prime}$-kinase increases efficacy of paclitaxel in in vitro and in vivo ovarian cancer models. Cancer Res 62: 1087-1092

$\mathrm{Hu}$ L, Zaloudek C, Mills GB, Gray J, Jaffe RB (2000) In vivo and in vitro ovarian cancer growth inhibition by a phosphatidylinositol 3-kinase inhibitor (LY294002). Clin Cancer Res 6: 880-886

Lane HA, Boulay B, Hattenberger M (2003) The orally active rapamycin derivative RAD001 has potential as an antitumor agent with a broad

antiproliferative activity: PTEN as a molecular determinant of response. Proc Am Assoc Cancer Res 44: 314. Abstract 1608

Le T, Hopkins L, Baines KA, Rambout L, Al Hayki M, Kee Fung MF (2006) Prospective evaluations of continuous weekly paclitaxel regimen in recurrent platinum-resistant epithelial ovarian cancer. Gynecol Oncol 102: $49-53$

Le XF, Hittelman WN, Liu J, McWatters A, Li C, Mills GB, Bast Jr RC (2003) Paclitaxel induces inactivation of p70 S6 kinase and phosphorylation of Thr421 and Ser424 via multiple signaling pathways in mitosis. Oncogene 22: $484-497$

Lee S, Yang W, Lan KH, Sellappan S, Klos K, Hortobagyi G, Hung MC, Yu D (2002) Enhanced sensitization to taxol-induced apoptosis by herceptin pretreatment in ErbB2-overexpressing breast cancer cells. Cancer Res 62 $5703-5710$

Magné N, Fischel JL, Dubreuil A, Formento P, Poupon MF, Laurent-Puig P, Milano G (2002) Influence of epidermal growth factor receptor (EGFR), p53 and intrinsic MAP kinase pathway status of tumour cells on the antiproliferative effect of ZD1839 ('Iressa'). Br J Cancer 86: 1518-1523

Mondesire WH, Jian W, Zhang H, Ensor J, Hung MC, Mills GB, MericBernstam F (2004) Targeting mammalian target of rapamycin synergistically enhances chemotherapy-induced cytotoxicity in breast cancer cells. Clin Cancer Res 10: $7031-7042$

Mori K, Kamiyama Y, Kondo T, Kano Y, Kodama T (2007) Phase II study of weekly chemotherapy with paclitaxel and gemcitabine as second-line treatment for advanced non-small cell lung cancer after treatment with platinum-based chemotherapy. Cancer Chemother Pharmacol 60: $189-195$

O'Donnell A, Faivre S, Burris III HA, Rea D, Papadimitrakopoulou V, Shand N, Lane HA, Hazell K, Zoellner U, Kovarik JM, Brock C, Jones S, Raymond E, Judson I (2008) Phase I pharmacokinetic and pharmacodynamic study of the oral mammalian target of rapamycin inhibitor everolimus in patients with advanced solid tumors. J Clin Oncol 26: $1588-1595$

O'Reilly T, Muller M, Hattenberger M, Vaxelaire J, Lane HA (2003) Antitumor activity of RAD001 in combination with cytotoxic agents. Proc Am Assoc Cancer Res 44: 136. Abstract 713

Pacey S, Rea D, Steven N, Brock C, Knowlton N, Shand N, Hazell K, Zoellner U, O'Donnell A, Judson I (2004) Results of a phase I clinical trial investigating a combination of the oral mTOR-inhibitor everolimus (RAD001) and gemcitabine in patients with advance cancers. J Clin Oncol 22(Suppl): 224s. Abstract 3120

Perez EA, Suman VJ, Rowland KM, Ingle JN, Salim M, Loprinzi CL, Flynn PJ, Mailliard JA, Kardinal CG, Krook JE, Thrower AR, Visscher DW, Jenkins RB (2005) Two concurrent phase II trials of paclitaxel/ carboplatin/trastuzumab (weekly or every-3-week schedule) as first-line therapy in women with HER2-overexpressing metastatic breast cancer: NCCTG study 983252. Clin Breast Cancer 6: 425-432

Perez-Tenorio G, Stal O, Southeast Sweden Breast Cancer Group (2002) Activation of $\mathrm{AKT} / \mathrm{PKB}$ in breast cancer predicts a worse outcome among endocrine treated patients. Br J Cancer 86: 540-545

Pham PT, Pham PC, Danovitch GM, Ross DJ, Gritsch HA, Kendrick EA, Singer J, Shah T, Wilkinson AH (2004) Sirolimus-associated toxicity. Transplantation 77: 1215-1220

Punt CJ, Boni J, Bruntsch U, Peters M, Thielert C (2003) Phase I and pharmacokinetic study of CCI-779, a novel cytostatic cell-cycle inhibitor, in combination with 5-fluorouracil and leucovorin in patients with advanced solid tumors. Ann Oncol 14: 931 -937

Ramalingam S, Barstis J, Perry MC, La Rocca RV, Nattam SR, Rinaldi D, Clark R, Mills GM, Belani CP (2006) Treatment of elderly non-small cell lung cancer patients with three different schedules of weekly paclitaxel in combination with carboplatin: subanalysis of a randomized trial. J Thorac Oncol 1: 240-244

Saal LH, Holm K, Maurer M, Memeo L, Su T, Wang X, Yu JS, Malmström PO, Mansukhani M, Enoksson J, Hibshoosh H, Borg A, Parsons R (2005) PIK3CA mutations correlate with hormone receptors, node metastasis, 
and ERBB2, and are mutually exclusive with PTEN loss in human breast cancer. Cancer Res 65: 2554-2559

Samuels Y, Wang Z, Bardelli A, Silliman N, Ptak J, Szabo S, Yan H, Gazdar A, Powell SM, Riggins GJ, Willson JK, Markowitz S, Kinzler KW, Vogelstein B, Velculescu VE (2004) High frequency of mutations of the PIK3CA gene in human cancers. Science 304: 554

Schuette W, Blankenburg T, Guschall W, Dittrich I, Schroeder M, Schweisfurth H, Chemaissani A, Schumann C, Dickgreber N, Appel T, Ukena D (2006) Multicenter randomized trial for stage IIIB/IV nonsmall-cell lung cancer using every-3-week versus weekly paclitaxel/ carboplatin. Clin Lung Cancer 7: 338-343

Shayesteh L, Lu Y, Kuo WL, Baldocchi R, Godfrey T, Collins C, Pinkel D, Powell B, Mills GB, Gray JW (1999) PIK3CA is implicated as an oncogene in ovarian cancer. Nat Genet 21: $99-102$

Stathopoulos GP, Malamos NA, Aravantinos G, Rigatos S, Christodoulou Ch, Stathopoulos J, Skarlos D (2007) Weekly administration of topotecan-paclitaxel as second-line treatment in ovarian cancer. Cancer Chemother Pharmacol 60: 123-128

Tabernero J, Rojo F, Calvo E, Burris H, Judson I, Hazell K, Martinelli E, Ramon y Cajal S, Jones S, Vidal L, Shand N, Macarulla T, Ramos FJ, Dimitrijevic S, Zoellner U, Tang P, Stumm M, Lane HA, Lebwohl D, Baselga J (2008) Dose- and schedule-dependent inhibition of the mammalian target of rapamycin pathway with everolimus: a phase I tumor pharmacodynamic study in patients with advanced solid tumors. J Clin Oncol 26: $1603-1610$

Tanaka C, O'Reilly T, Kovarik JM, Shand N, Hazell K, Judson I, Raymond E, Zumstein-Mecker S, Stephan C, Boulay A, Hattenberger M, Thomas G, Lane HA (2008) Identifying optimal biologic doses of everolimus
(RAD001) in patients with cancer based on the modeling of preclinical and clinical pharmacokinetic and pharmacodynamic data. J Clin Oncol 26: $1596-1602$

Vahid B, Marik PE (2008) Pulmonary complications of novel antineoplastic agents for solid tumors. Chest 133: $528-538$

Vanderweele DJ, Rudin CM (2005) Akt-mTOR signaling mediates resistance to antimicrotubule chemotherapeutic agents. Proc Am Assoc Cancer Res 46: 775. Abstract 3293

Yamamoto N, Tsurutani J, Yoshimura N, Asai G, Moriyama A, Nakagawa K, Kudoh S, Takada M, Minato Y, Fukuoka M (2006) Phase II study of weekly paclitaxel for relapsed and refractory small cell lung cancer. Anticancer Res 26: 777-781

Yeh KH, Lu YS, Hsu CH, Lin JF, Hsu C, Kuo SH, Li SJ, Cheng AL (2005) Phase II study of weekly paclitaxel and 24-hour infusion of high-dose 5fluorouracil and leucovorin in the treatment of recurrent or metastatic gastric cancer. Oncology 69: 88-95

Yu K, Lucas J, Zhu T, Cai P, Tsao R, Gong Y, Li F, Chaudhary I, Desai P, Ruppen M, Fawzi M, Gibbons J, Ayral-Kaloustian S, Skotnicki J, Mansour T, Zask A (2005) PWT-458, a novel pegylated-17-hydroxywortmannin, inhibits phosphatidylinositol 3-kinase signaling and suppresses growth of solid tumors. Cancer Biol Ther 4: 538-545

Yusuf RZ, Duan DE, Lamendola RT, Penson RT, Seiden MV (2003) Paclitaxel resistance: molecular mechanisms and pharmacologic manipulation. Curr Cancer Drug Targets 3: 1-19

Zhou X, Tan M, Stone Hawthorne V, Klos KS, Lan KH, Yang Y, Yang W, Smith TL, Shi D, Yu D (2004) Activation of the Akt/mammalian target of rapamycin/4E-BP1 pathway by ErbB2 overexpression predicts tumor progression in breast cancers. Clin Cancer Res 10: 6779-6788 